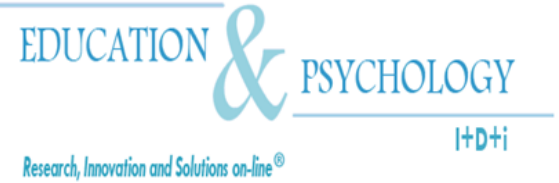

\section{Electronic Journal of Research}

in Educational Psychology

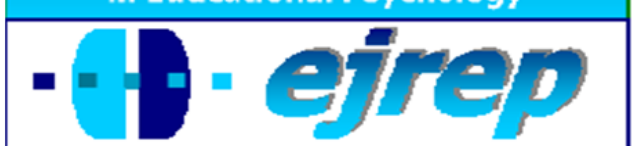

\title{
Academic Identity Status and the Relationship to Achievement Goal Orientation
}

\author{
Christopher A. Was ${ }^{1}$, Ibrahim Al-Harthy ${ }^{1}$, \\ Maura Stack-Oden ${ }^{1}$, Randall M. Isaacson ${ }^{2}$ \\ ${ }^{1}$ Department of Educational Foundations and Special Services, \\ Kent State University, Kent, $\mathrm{OH}$ \\ ${ }^{2}$ School of Education, Indiana University South Bend, South Bend, IN
}

USA

Christopher Was. 405 White Hall, Kent State University. Kent, OH 44240 USA. E-mail: cwas@,kent.edu (C) Education \& Psychology $\mathrm{I}+\mathrm{D}+\mathrm{i}$ and Editorial EOS (Spain) 


\begin{abstract}
Introduction. Two constructs that have received a great deal of attention in Educational Psychology research are Achievement Orientation and Identity Status. However, the relationship between these two constructs has not received the attention that the current researcher feel is warranted. The impetus for the current study is the paucity of research in this area.

Method. The current study employed a self-report measure of academic identity status founded in Marcia's theory of identity states. A second measure adopted from Elliot's trichotomous framework of goal orientation was used to capture students' achievement goal orientation. Data collected from 407 undergraduate students was submitted to correlational and path analyses to examine the relationship between the two constructs.

Results. Results indicated that the specific academic identity status of a student is related to the type of academic goals one adopts.

Discussion or Conclusion. The results of our analysis support our hypothesis that a relationship exists between a student's academic identity status and the types of goals a student will adopt. Implications for educators and research are discussed.
\end{abstract}

Keywords. achievement goals; identity status; goal orientation; academic identity

Received: 01/14/09 Initial Acceptance: 01/14/09 Final Acceptance: 06/03/09 


\section{Rango de identidad académica y su relación con la orien- tación de meta de logro}

\section{Resumen}

Introducción. La meta de logro y el rol de identidad han sido dos constructos que han recibido una gran atención en la investigación de la Psicología Educativa. Sin embargo, la relación entre ambos no ha recibido la atención necesaria. La razón del presente estudio es la escasez de estudios en esta área.

Método. La presente investigación se basa en el análisis de medidas de autoinforme relativas al rol de identidad académica establecido en la teoría de Marcia. Una segunda medida, adoptada del esquema triárquico de Elliot sobre la meta de logro, se utiliza para valorar la orientación de logro de los estudiantes. Los datos de los 407 estudiantes universitarios participantes en el estudio fueron sometidos a análisis correlacionales para examinar la relación entre ambos constructos.

Resultados. Los resultados señalan que el rol de identidad académica del estudiante está relacionado con el tipo de metas de académicas que éste se propone.

Discusión y Conclusiones. Los resultados del análisis apoyan la hipótesis inicial que señala la relación existente entre el rol de identidad académico y los tipos de metas que el estudiante adopta. Se discuten las implicaciones para los educadores y futuras investigaciones.

Palabras Clave: metas de aprendizaje; identidad; orientación de la meta; identidad académica Recibido: 14/01/09 Aceptación inicial: 14/01/09 Aceptación final: 03/06/09 


\section{Introduction}

The factors involved in academic success are innumerable. Considering the achievement of college students, it is evident that there is a multitude of influences on achievement, learning, and student retention. However, in recent Educational Psychology literature a few specific factors have been studied in some depth. Ego-identity development and achievement goal orientation are two such factors. Identity development and identity processing styles have been demonstrated to have an impact on academic achievement (e.g., Berzonsky, 1989).

Achievement goal theory or goal orientation theory has also received a good deal of attention and the different goal orientations have often been studied in relation to achievement outcomes (see Harackiwiecz, Barron, \& Elliot, 1998 for a review). Academic goals are defined as motivation, academic in nature, that guides students' behavior in academic or classroom settings (De la Fuente, 2004). Achievement goal theory states that students have distinctive orientations towards certain types of goals. These orientations in part determine the strategies students adopt in academic contexts. It the current study, we examine the relationship between the types of goals college students set and the students' academic identity status as a domain specific part of the overall ego-identity.

Erikson $(1963,1968,1980)$ proposed a psychosocial theory of development in which adolescence is described as a time of identity crisis. Erikson elaborated that late adolescence and early adulthood are a time when individuals make choices regarding their values, beliefs, and goals by exploring options and experiencing crises. The decisions that an individual makes regarding self-relevant choices, result in commitment to an identity. The processes involved in establishing an identity, as well as the status of the identity, affect how an individual will cope with adversity, interact with others, make decisions about vocation paths, and other important life decisions.

In an elaboration and extension of Erikson's work, Marcia (1966, 1980, 1993) named four identity statuses in which an individual may reside in the process of identity development. Germane to Marcia's identity states are Erikson's (1963) concepts of crises and commitment. Crisis refers to an intense examination of values and beliefs in relation to one's self view. While commitment refers to making decisions as to the values and beliefs, one adopts. 
According to Marcia, the relationship between crisis and commitment determines which identity state an individual resides.

Identity foreclosure refers to adopting the goals, values, and lifestyle significant others have prescribed for an individual. These others are typically parents. In foreclosure, the individual experiences commitment, without an internal analysis of the values and beliefs to which they commit. When an individual has not experienced either a crisis nor has he/she committed to a set of values, goals, or beliefs, this individual is in identity diffusion. Often this individual occurs to have made no conclusion about his or her identity and has no clear direction. Identity moratorium refers to the gradual exploration of personal and occupational choices. This is a time of instability regarding values, goals, and beliefs, reflecting the experience of a crisis, without the resulting commitment. Identity achievement occurs when one has critically analyzed values in comparison to their self-view and makes choices to pursue certain options. These individuals have experienced both crisis and commitment.

The relationship between identity development and academic achievement is one in which researchers and educators alike have a stake. Identity achievement has been argued to be essential to academic success (Berger, 1998; Berzonsky, 1989). In a study of 208 middle school students, Streitmatter (1989) demonstrated that students with an achieved sense of identity performed better on a measure of mathematics achievement than students in the other identity statuses. Similarly, Lange and Byrd (2002) found in a study of first year university students, that not only did those with an adult identity employ more effective study strategies, but were more accurate at evaluating their probability of success in a particular course.

Epstein (1973) proposed that identity structure is an unconsciously constructed selftheory. In other words, an individual's interpretation of environmental and social information, that is self-relevant, is supported by a framework that contains self-schema (Schank \& Ableson, 1977). This self-theory determines the types of strategies one uses to interpret selfrelevant information in day-to-day life, as well as approaches to problem solving and decision making. Berzonsky (1990) proposed that this self-theory is in part determined by the identity development status in which one is currently found and that the identity status in turn predicts the identity processing orientation one adopts (Berzonsky, 1989). Due to the findings that identity states relate to different behavioral and academic outcomes, Berzonsky $(1989,1992)$ 
defined three identity processing orientations that in turn produce identity processing styles, that directly relate to Marcia's (1966) identity statuses.

Berzonsky (1992) described self-identity as a "self-constructed theory of self" (p.771) and contended that processing orientations are grounded in this conceptualization of self. Berzonsky, Nurmi, Kinney, and Tammi (1999) described the model of identity processing orientations as operating on three levels:

"Identity style, the most general level, pertains to the array of strategies that individuals characteristically use or prefer to utilize across a diversity of environmental and social contexts. Social-cognitive strategies consist of organized sets or systems of the basic behavioral and cognitive units. The most specific level consists of the actual cognitive and behavioral responses individuals perform as they negotiate identity conflicts and make decisions. (p. 106)."

The different identity processing styles utilize different cognitive strategies to either modify or maintain the self-identity. Berzonsky (1992) proposed three identity processing orientations: information orientation, normative orientation and diffuse/avoidant orientation. Berzonsky's (2003) third version of the identity style inventory (ISI 3) measured three identity processing styles adopted by individuals based on their processing orientation. Information oriented individuals seek out self-relevant information when making identity relevant decisions. These individuals are thought to reside in the moratorium stage or achieved stage. Individuals with a foreclosed identity status utilize a normative orientation, conforming to the expectations of significant others, most often their parents. Those who procrastinate and avoid making self-relevant decisions, as well as resisting considering information that is inconsistent with their view of their identity are considered diffuse/avoidant in their orientation. These individuals are in the diffuse identity status.

The concept of identity processing orientation is concerned with the cognitive processing of self-relevant information. However, Berzonsky (1990, 2003) also demonstrated that commitment to an identity is related to identity styles, and may act as a mediator between processing styles and outcome behaviors. As previously described, commitment refers to selecting options regarding self-relevant decisions and is often the conclusion of the identity achievement vs. role confusion crisis (Erikson, 1963, 1968). Described by Marcia and Archer (1993) as an important step in late adolescence, commitment is defined by Marcia and Archer 
"a definitive choice among possibilities and adherence to the chosen direction in the face of distracting and inviting alternatives (p. 208)." Individuals who have experienced the "identity crisis" and have made choices regarding identity relevant issues are said to be identity achieved. Individuals who have made these choices without experiencing exploring options are identity foreclosed. The individual who experiences a crisis and explores options, but has yet to make choices, are said to be in moratorium. Those who have not experienced the crisis and have made no self-relevant choices are in diffusion.

Significant to the current study is research that indicates that the processing styles are correlated to students' ability to adapt to university life. Although Erikson $(1963,1968)$ originally hypothesized the identity vs. role confusion crisis to be an attribute of adolescence, a more recent version of his theory stated that this crisis might occur in early adulthood (Erikson, 1982). "Adolescence and the ever more protracted apprenticeship of the later school and college years can, $[\ldots]$ be viewed as a psychosocial moratorium: a period of sexual and cognitive maturation and yet a sanctioned postponement of definitive commitment (Erikson, 1982: pp. 74-75)." Schmidt and Hunt (1994) provided evidence that there are individual differences in first-year college students' psychosocial development and that self-perceptions can greatly influence the degree to which students are prepared to participate in college life. In light of this perspective, it is clear that how one copes with the transitions that occur during entry into university life would be greatly impacted by identity status and in turn by the identity processing styles the individual adopts to manage self-relevant information. Berzonsky (1989, 1993) provided evidence that student's academic achievement is in part affected by their identity processing styles. Lange and Byrd (2002) demonstrated that university students who had committed to aspects of their identity were more likely to feel as if they could plan and implement effective study strategies. Boyd, Hunt, Kandell, and Lucas (2003) found that male university students that were diffuse/avoidant in their identity processing style were less likely to be in good academic standing three semesters after matriculation as compared to their counterparts utilizing other identity processing styles.

It is possible that identity processing style not only affects cognitive processing strategies, but also the way students adapt to university life in general. Berzonksy and Kuk (2002, 2005; see also Berzonsky, Nurmi, Kinney, \& Tammi, 1999) concluded that students with an informational orientation are best prepared to effectively adapt within a university context, whereas those with a diffuse/avoidant orientations are most apt to encounter difficulties. 
Important to the current study is the assumption that identity status is context specific. In other words, individuals may be in a specific identity status, and in turn adopt different processing orientations, in specific areas of their lives. Others have proposed specific contexts in which development occurs. Bosma (1992) cross-validated data from an interview protocol and a questionnaire regarding topics about which adolescents may have concerns. The data from 97 interviews and 303 questionnaires collected with teens from the Netherlands revealed four popular categories in which teens had concerns: education/future occupation, leisuretime, friendship, parents/home. These areas of concern in turn represent distinct areas where identity status may be in unique stages. For example, in a study undertaken to develop an occupational identity status scale, Melgosa (1987) demonstrated that occupational concerns represent only one part of ego-identity status. Archer (1993) states that individuals may be in one identity statuses in one life domain, while being in different identity statuses in other domains. Marcia and Archer (1993) identify identity status domains similar to those areas of interest indicated by Bosma's (1992) study.

Because an individual may be in a different status in various contexts, the current study employed a measure of academic identity status that was found to account for a greater amount of variance in the strategies students adopt in achievement settings than a measure of more general identity processing orientation (Was \& Isaacson, 2008). The self-concept literature supports the argument that academic identity needs to be distinguished from a more global identity. The evidence for contextualizing self-concept has been repeatedly supported by research based on the model proposed by Shavelson, Hubner, and Stanton (1976; see also Marsh, 1990). The original model proposed by Shavelson et al. was composed of a hierarchical structure of self concept with specific subcomponents. Included in the subcomponents was an academic self-concept with even further subcomponents subsumed under academic self-concept (e.g., math and English) being highly correlated. Recent studies have found that the subdivisions of academic self-concept were not correlated (Marsh, Byrne, \& Shavelson, 1988). In either case, previous research supports the hypothesis that general self-concept contains at minimum a subdivision of academic self-concept from the more global self view.

Extensive research has supported the conclusion that academic self-concept and academic achievement are highly related. In a review of the literature, Marsh (1993) found that there was a substantial amount of research supporting the conclusion that academic achievement was related to academic self-concept, but not related to global measures of self-concept. 
Using structural equation modeling and a sample of 603 high school students, Marsh and Yeung (1997) found that prior achievement tended to predict academic self-concept, but there were also obvious effects of prior academic self-concept on subsequent achievement.

As previously discussed, the identity statuses identified by Marcia (1966, 1980, 1993) lead to identity processing styles proposed by Berzonsky $(1989,1992)$. These processing styles determine the types of strategies an individual uses to process self-relevant information. One hypothesis is academic self-concept is in part determined by the academic identity status in which an individual is currently found. Furthermore, the academic identity status in which a student resides will affect the types of strategies and behaviors one adopts in an academic achievement setting.

To test this hypothesis Was and Isaacson (2008) developed a self-report measure of academic identity status. The academic identity measure (AIM) was designed to distinguish four academic identity statuses: foreclosed, moratorium, diffuse, and achieved. Classifications for the AIM were chosen based on Marcia's (1966) identity statuses. In the measure, academic identity foreclosure was represented by questionnaire items designed to capture a student's commitment to academic values and ideals adopted based on the influence of significant others. (“An important reason I choose to go to college was my family wanted me to go.") Academic identity moratorium was operationalized as a time of academic indecision in which a student attempts to reach conclusions about their academic values and goals. Because this period represents an uncertainty regarding an academic identity, the items in the self-report questionnaire reflect the natural tendency of adolescents and young adults to explore the relevance of academic values that occur to the individual as self-relevant. Take for example the following item: "My priorities in school are in transition. Some days I am serious, others days I have other priorities." This item reflects the individual's academic indecision and consideration of different academic values.

Academic identity diffusion refers to a lack of exploration or commitment often accompanied by procrastination regarding decision pertaining to academic values. ("Finding time to study often takes a back seat to social and recreational activities.") Finally, academic identity achievement refers to a commitment to a set of academic values following a period of exploration. ("Although I have many priorities, learning in school is always one of my most important goals.”) Important to the current study was an analysis conducted using hierar- 
chical multiple regressions. These analyses allowed for the testing of the hypothesis that academic identity status accounts for unique variance in the learning strategies students adopt, beyond the variance accounted for by more general identity processing styles.

The findings of Was and Isaacson (2008) suggest that identity stages and identity processing styles are not generalized to all areas of life, but might be compartmentalized. In particular, academic identity status was found to account for unique variance in the study strategies college students employ. Findings such as these have led us to inquiry regarding relationship between goal orientations and identity statuses.

\section{Achievement Goal Theory}

Achievement goal theory assumes that students adopt specific patterns of goals when approached with achievement tasks. These patterns of goals in turn influence the behavior patterns students adopt in achievement contexts (see Elliot, 2005 for a review). Achievement goal theorists posit that the type of orientation adopted at the outset of an activity creates a framework for how individuals interpret, evaluate, and act on achievement-relevant information and experience achievement settings. The dominant theoretical approach to goal orientation in academic settings has been that of mastery vs. performance orientations. Students with mastery goals focus on learning material and mastering the task-at-hand. Students who set performance goals are concerned with demonstrating their ability and performance as measured by their relative standing to others' achievements. Students with performance goals attempt to look competent or avoid looking incompetent when compared to others (Dweck, 1986; Dweck \& Elliot, 1983; Dweck and Leggett, 1988; Elliot \& Dweck, 1988; Lepper, 1988). The distinction between these two different goal orientations has been the focus in achievement motivation and self-regulation in the majority of past research (e.g., Ames, 1992; Dweck and Legget, 1988).

In the literature of the past twenty years, mastery goals have been hypothesized to be the appropriate approach to enhancing learning, increasing self-efficacy, effort, and persistence as well as the goal orientation, which would encourage the use of more effective metacognitive and cognitive strategies. In contrast to students with a mastery orientation, much research has demonstrated that students attuned to performance goals are likely to become 
frustrated in the face of failure and attribute success and failure to more external factors such as luck, task difficulty, and an uncontrollable lack of ability (Dweck, 1986).

However, in many instances researchers have demonstrated that under certain circumstances, performance goal orientation leads to higher achievement (see Brophy, 2005 for a review). This revised view of goal theory makes a distinction between performance-approach and performance-avoidance goals. Students who are performance approach oriented view themselves as having a good deal of ability and wish to measure themselves against others performance hence, demonstrating their ability. Others have described a similar orientation and have labeled this orientation Ego-Social orientation. Somuncuoglo and Yildirim (1999) state that ego-social orientation leads to an emphasis on high grades and outperforming others to gain approval and enhance ones self-esteem. Performance-avoidance orientation is grounded in one viewing them-self as lacking ability and therefore wishing to avoid public demonstrations of achievement that would confirm their lack of ability. Students with a performance-avoidant orientation adopt failure-avoiding strategies as a means of protecting their self-worth. These strategies include weak efforts, avoiding academic risks, setting unrealistically high or low goals, claiming not to care and procrastination.

In order to understand the relationship between the goal orientations and academic identity, below we discuss how different goals relate to other motivational variables as they were investigated in previous research. There is growing research literature investigating the impact of goal orientation on students' performance. In the literature, the goal orientations have been approached in different ways as we see in the discussion below. In recent years, we have seen a convergence of theory and research around goal orientation (see Elliot, 2005; Was, 2006 for a review). These goals represent different ways of pursuing competence in achievement situations. Not only is the relationship between the goal orientation and students' achievement investigated, but also the relationships of these goals with other theories' constructs, such as self-efficacy, task value, and self-regulation receives great attention. Many studies have found that mastery goals are positively related to a high sense of self-efficacy (Anderman \& Young, 1994; Meece, Blumenfeld, \& Hoyle, 1988; Middlleton, Kaplan, \& Midgley, 1998; Middleton \& Midgley, 1997; Midgley \& Urdan, 1995). For example, Middleton and Midgley (1997) examined the relationship between 703 sixth-graders' self-efficacy, self-regulation, academic goals, and academic achievement in mathematics. They used a trichotomous framework of goal orientation. Scales were adapted from Patterns of Adaptive 
Learning Survey (PALS) to measure mastery goals, performance-approach goals, and academic efficacy. They also developed another scale to measure performance-avoidance goals. The self-regulated learning scale was adapted from measures developed by Zimmerman and Martines-Pons (1988) and Pintrich, Smith, Garcia, and McKeachie (1991) (as cited on Middleton and Midgley, 1997). Students' academic achievement was computed on the basis of students' final grade in math in the previous year. Middleton and Midgley found that mastery goal orientation positively predicted academic self-efficacy and reports of the use of selfregulated learning strategies. In contrast, performance-avoidance goals were a moderate negative predictor of self-efficacy and positive predictors of test anxiety. Surprisingly, performance-approach goals did not significantly predict self-efficacy or self-regulated learning. However, these results contradict other investigations in which the relationship between selfefficacy and performance-approach goals has been found to be positive (Midgley \& Urdan, 1995; Wolters, Yu, \& Pintrich, 1996). For instance, Wolters et al. (1996) investigated the relationship between goals orientation, motivational beliefs, self-regulation and the academic performance of seventh and eighth graders in four different subject areas, math, English, social studies and science. They defined different components of goal orientation including learning goals, extrinsic goals, and relative ability goals. Relative ability goal orientation was defined as students' reflection of how strongly they adopted goals related to doing better than other students. The goal-orientation scale was again adapted from the PALS. The motivational beliefs included task value, self-efficacy, test anxiety, and cognitive strategy use, the last of which included organizational, rehearsal, and elaboration strategies. Subscales from motivated strategies for learning questionnaire (MSLQ; Pintrich, P. R., National Center for Research to Improve Postsecondary Teaching and Learning, 1991) were adapted to measure the motivational variables and self-regulation.

Students' grades in four subject areas in the first and second semesters (Time 1 and Time 2) were collected from school records and were standardized within classrooms. The results demonstrated that learning goals as well as relative ability goal orientation positively predicted motivational beliefs, strategy use, and self-regulation, but it was not related to test anxiety. More interestingly, learning goal orientation was not a strong predictor of students' grade in any of four subjects at Time 1, whereas relative ability goal orientation positively predicted students' task value, self-efficacy, performance, and cognitive strategy and selfregulatory strategy use. Moreover, the results of the Wolters et al. (1996) study demonstrated that learning goal orientation was the single best predictor of task value. This study produced 
results similar to those of other research regarding the positive relationship between mastery goal orientation and the use of effective learning strategies (Ames \& Archer, 1988; Anderman \& Young, 1994; Nolen, 1988; Sankaran \& Bui, 2001; Somuncuoglu \& Yildirim, 1999).

The connection between achievement goal orientation and academic identity status becomes clear in light of findings regarding identity processing style and academic achievement. Berzonsky and Kuk (2000) pointed out the differences in identity processing styles accounted for significant variation in the students' progress on measures of academic autonomy, educational involvement, and mature interpersonal relationship. They suggested that students with an informational identity style (related to identity achievement and moratorium) are best prepared to adapt within a university context. This was partially based on the finding that information processing style was positively correlated with GPA and diffused/avoidant style was negatively correlated with GPA. If, as Berzonsky and Kuk claim, students with an information orientation are more academically autonomous and demonstrate greater educational involvement, it would suggest that these students also demonstrate academic persistence and greater self-efficacy. Which in turn are characteristics of a mastery achievement goal orientation. This led us to hypothesis that there is a positive relationship between a mastery-goal orientation and the achievement and moratorium academic identity statuses.

Berzonsky and Kinney (1995) demonstrated that normative students display goal orientated behavior in an academic setting. It was our assumption that normative students have a need to display competence to the significant others who have prescribed an academic identity for these students. Based on this assumption we hypothesized that students in a foreclosed academic identity state would be performance orientated in achievement goals. We hypothesize that academic identity foreclosure will be correlated to both performance-approach and performance-avoidant orientations. Whether an academically foreclosed student is performance-approach or performance-avoidant orientated likely hinges on whether there is a sense of academic self-efficacy.

As Berzonsky and Kinney (1995) clearly demonstrated, students with a diffuse/avoidant processing style are ill-suited for university life. Their explanation describes the diffused student as lacking educational involvement, lacking academic purpose, and low autonomy. It is our assumption that students with little academic purpose and low autonomy suffer from low-self-efficacy. Elliot \& Harackiewicz (1996) proposed a constellation of help- 
less motivational responses, including a preference for easy or difficult tasks, effort withdrawal in the face of failure, attribution of failure to lack of ability, decreased task enjoyment, and focus on demonstrating ability as measured by their relative standing to others result from the adoption of a performance-avoidant goal orientation. Based on the Berzonsky and Kinney findings, and the description of Elliot \& Harackiewicz, we hypothesized that students in academic diffusion would be performance-avoidant in the achievement goal orientation.

Finally, as operationalized in the Was and Isaacson (2008) study, academic moratorium is a time of indecision regarding one's academic self. This is a time when decisions about academic goals and aspirations are in flux. Although Berzonsky and Kinney (2005) demonstrated that informational identity processing style was positively correlated to academic performance, Was and Isaacson measured moratorium as a time of indecision. It is likely that this indecision would have a negative impact on academic performance.

It is hypothesized that the academic identity status that is most representative of a students current standing will correlate with specific achievement goal orientations. We predicthat a diffuse academic identity will correlate with a performance avoidant goal orientation. Recall that diffusion in academic identity is a time when the individual has not explored academic values and ideals, not has the individual made a commitment to academic values. It is likely that this lack of commitment to academic progress will lead the student to adopt academic strategies designed to avoid demonstrating a lack of competence (i.e. self-handicapping strategies) while not investing a great deal of effort into learning or performance.

Academic foreclosure is likely to have a strong relationship with both performance goal orientations. Academic foreclosure occurs when the student adopts the academic values and ideals most likely prescribed by their parents. This student has adopted these ideals and are committed to demonstrating that he/she is capable of the academic life prescribed or determined avoid demonstrating the inability. Hence, these students are more likely than others to adopt goals related to performance and not learning goals.

Academic acheved status is hypothesized to be the one academic identity status to most strongly related to mastery goals. A student with an achieved academic identity has explored academic, values, beliefs, and interests and has committed to the academic ideals which they have chosen freely from an informed perspective. The academically achieved stu- 
dent is likely to be studying in a field for which they have an intererst and desire to master the topic. This is an inherent part of the mastery goal orientation.

To test all of the above hypotheses, students enrolled in an educational psychology course were administered the AIM and the AGO. The educational psychology course is taken by mostly freshmen and sophomores as this course must be completed successfully before being admitted to the teacher education program at their university.

\section{Method}

\section{Participants}

Four hundred seven undergraduates at a medium sized Midwestern university, enrolled in an introductory educational psychology course received course credit for their participation in the study. Approximately $4 \%$ of the data was missing due to incomplete data or attrition. The total number of complete files was 391 . Females represented $74 \%$ of the sample. Participants in the study were freshmen and sophomores at enrolled in the course as a requirement for entry into the teacher education program at the university.

\section{Measures}

Academic Identity Status: The academic identity measure (AIM; Was \& Isaacson, 2008) employed in the current study contained four subscales, each with ten items. The four 10-item subscales include items designed to measure four academic identity states: Moratorium, Foreclosed, Diffuse, and Achievement. Participants responded to each of the items on a 5-point Likert scale of 1 (not at all like me) to 5 (very much like me). The internal reliability (coefficient alpha, $N=407$ ) of the four subscales was as follows: Moratorium $=.85$, Foreclosed $=.77$, Diffuse $=.76$, and Achievement $=76$.

Goal Orientation: Elliot's (1999) achievement goal items, which were adapted from the Elliot and Church's (1997) Achievement Goal Questionnaire (AGQ) items were used as the measure of goal orientation. These scales are based on a trichotomous framework of achievement goal orientation (see Elliot, 1999). Each of the three scales included six ques- 
tions. Participants responded to each of the items on a 5-point Likert scale of 1 (not at all like me) to 5 (very much like me).The internal reliability (coefficient alpha, $N=407$ ) of the three subscales for the current study was as follows: Mastery $=.56$, Performance-Approach $=.61$, and Performance-Avoidant $=63$.

\section{Design and Procedures}

The measures used in the current study were completed online by each participant with an imposed deadline to complete the questionnaires by specific dates defined by the course syllabus.

\section{Results}

Table 1 displays the descriptive statistics of the summed scores of the AIM subscales and AGQ subscales as well as the Pearson correlations among all measures. Correlations occurred in the hypothesized directions. Foreclosed academic identity status positively correlated with performance approach goal orientation and peformance avoidant goal orientation $(r=$ .27 and $r=.50$ respectively). Academic diffusion correlated mastery $(r=-.39)$ and with performance avoidant goals $(r=.50)$. Academic moratorium also correlated negatively with mastery and in a postitive direction with performance avoidant goals $(r=-.39$ and $r=.26$ respectively). Lastly, achieved academic identity correlated with mastery goals $(r=.46)$ and negatively correlated with peformance avoidant goals $(r=-.18)$. A subsequent path analyses revealed a model of the relationship between the AIM and the AGQ that supported our hypothesis. 
Table 1. Means, Standard Deviations, and Correlations Between The Academic Identity Measure and the Achievement Goal Questionairre.

\begin{tabular}{llllllllll}
\hline Variable & Mean & S. Dev. & 1 & 2 & 3 & 4 & 5 & 6 & 7 \\
\hline 1. AIM-Foreclosure & 26.57 & 6.33 & .77 & & & & & & \\
2. AIM-Diffusion & 18.40 & 4.76 & .25 & .76 & & & & & \\
3. AIM-Moratorium & 27.17 & 7.27 & .32 & .67 & .85 & & & & \\
4. AIM-Achievement & 39.14 & 4.82 & -.21 & -.71 & -.63 & .76 & & & \\
5. AGQ-Mastery & 25.59 & 2.72 & -.10 & -.39 & -.37 & .46 & .56 & & \\
6. AGQ-Performance- & 17.69 & 5.21 & .27 & -.04 & -.09 & .12 & .11 & .61 & \\
Approach & & & & & & & & & \\
7. AGQ-Performance- & 19.10 & 4.80 & .50 & .26 & .34 & -.18 & -.11 & .15 & .63 \\
Avoidant & & & & & & & & & \\
\hline
\end{tabular}

Diagonal values are Cronbach's Alpha internal consistency reliability estimates. AIM = Academic Identity Measure; $r>.18, p<.05$ (2-tailed); $r>.25, p<.01$ (2-tailed)

A path model that included a predictive path from all AIM subscales to all AGQ subscales supported the hypothesized relationships between academic identity status and achievement goal orientations (see Figure 1). Previous data collected using the AIM indicated moderate correlations between the various subscales, therefore correlations between AIM subscales were included in the path analysis. Correlations between the various goal orientation subscales were not included because of the conflicting data as regarding the nature of the correlations between the measures of these constructs and therefore allowing for the evaluation of a more parsimonious model. The path analysis was conducted by summing participants scored for each item within a subscale for each of the AIM and AGO subscales. Path analyses were then conducted using Amos 5 (Arbuckle, 2003). The Chi-square test was nonsignificant, $X^{2}(3, N=391)=4.57, p=.21$ other fit indices also indicated the model fit was acceptable. The root mean square error approximation $($ RMSEA) $=.037$. RMSEA values of less than .08 indicate adequate fit (Browne and Cudeck, 1992), and finally was CFI $=.998$. A number of parameters estimates in the model were not significant. However, several of the relationships between constructs were significant (see Table 2). Significant path coefficients germane to the current study include the path between foreclosed academic identity and peformance approach goal orientation $(b=.29, S E=.04, p>.001)$, the path between foreclosed academic identity and peformance avoidant goal orientation $(b=.34, S E=.04, p$ $>.001)$, the path between moratorium academic identity and peformance avoidant goal orientation $(b=.13, S E=.03, p>.001)$, and between achieved academic identity and mastery goal orientation $(b=.19 S E=.04, p>.001)$. 
Table 2. Parameter estimates for significant Hypothesized relations

\begin{tabular}{lllll}
\hline AIM & AGQ & $b$ & SE & P \\
\hline Foreclosed & Perf-Approach & .292 & .043 & .001 \\
Foreclosed & Perf-Avoidant & .340 & .036 & .001 \\
Moratorium & Perf-Avoidant & .132 & .031 & .001 \\
Achievement & Mastery & .187 & .039 & .001 \\
\hline
\end{tabular}

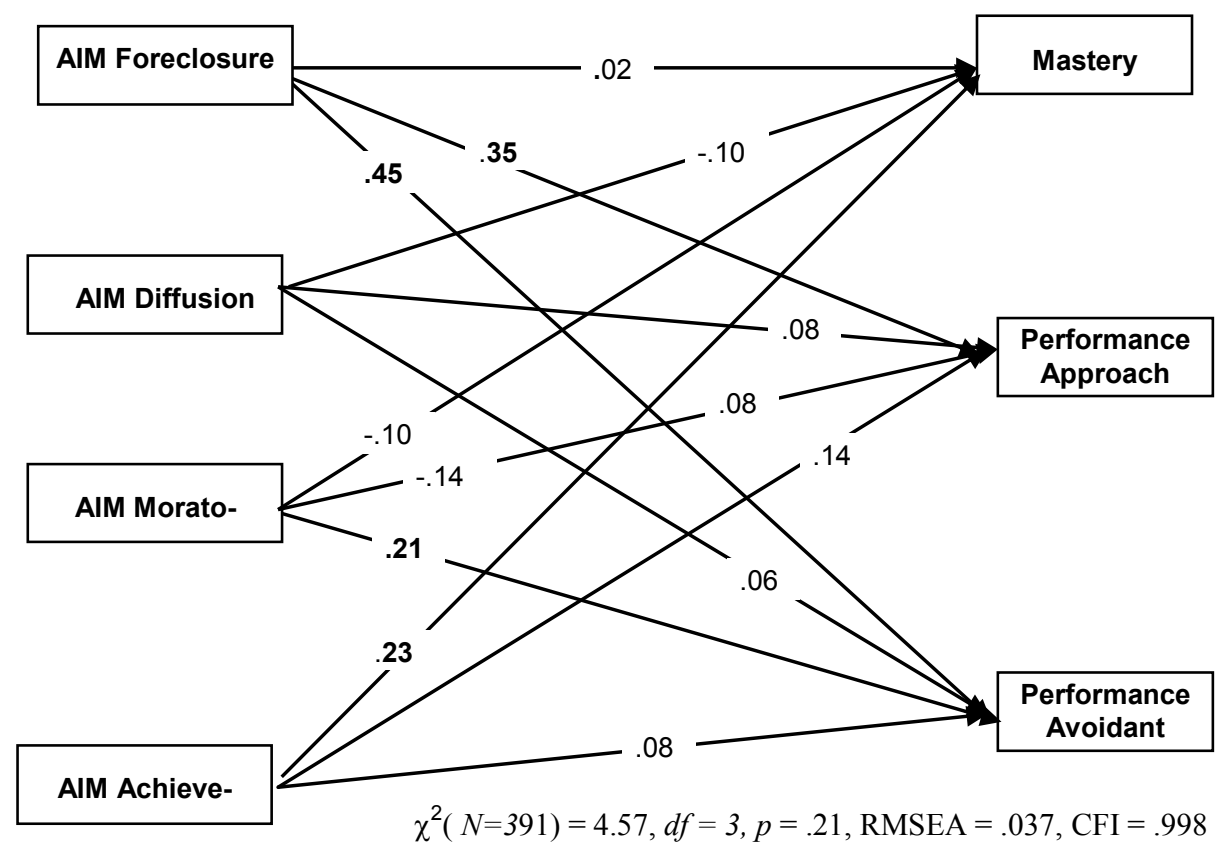

Figure 1. Path diagram with standardized parameter estimates 


\section{Discussion}

The results of our analysis support our hypothesis that a relationship exists between a student's academic identity status and the types of goals a student will adopt. However, the results also indicate that there is a great amount of variance not accounted for in our path model. Both of these issues will be addressed in the following discussion.

The analysis indicated that AIM-foreclosure had a positive correlation with both AGQ-performance-avoidant and performance-approach. Our interpretation is that students who are in academic identity foreclosure seek approval from parents, friends, and teachers. Because these students have adopted the academic identity prescribed for them by significant others, their goals are driven by a need to demonstrate they are capable of fulfilling these prescribed academic identities. It is our hypothesis that the mediating variable, which determines whether the foreclosed student adopts Performance-Approach or Performance-Avoidant goals, is self-efficacy.

Self-efficacy (Bandura, 1977, 1991) is one's perception of their ability to succeed at a specific task. Goals are the criterion for judging one's abilities. It is our contention that students with high self-efficacy adopt performance-approach goals in order to demonstrate ability to their significant others. Students in a foreclosed academic identity status with low selfefficacy adopt avoidant goals to hide their perceived lack of ability. This hypothesis has not yet been tested but warrants investigation.

As discussed in the literature review, the academically diffuse student demonstrates little educational involvement and suffers from low autonomy. Previous studies have suggested that the diffuse/avoidant student is least prepared to achieve academically (e g., Boyd et al, 2003). The current analyses revealed a negative relationship between the diffuse/avoidant academic identity status and mastery goals. Although this relationship is weak in the context of the path model, the simple bivariate correlation suggests that there is a relationship between the two variables. In the context of the current study, this student may see challenge as a threat and is therefore unlikely to set mastery goals.

The results supported our assumptions in that AIM-Moratorium negatively correlated with AGQ-Mastery goal orientation and positively with AGQ-Performance-Avoidant orienta- 
tion. This finding appears contradictory to the assumption that students in moratorium may seek self-relevant information. That is, information that tells them about the skills they have and those they do not. However, as operationalized in the AIM, academic moratorium is a time in which academic identity is in transition. During this time, students are attempting to determine if academic pursuits fit within their self-view. Theoretically, it would appear that setting mastery goals might provide this self-relevant information because students in moratorium discover what they are capable of by using learning strategies, working through challenges and maintaining a positive attitude toward their classes. However, the positive relationship with AGQ Performance-Avoidant goals can be explained by both the need for selfrelevant information and the lack of commitment to identity. One interpretation of the negative correlation with mastery goals is that students in moratorium have yet to determine whether academic pursuits fit their self-theory. In turn, adopting specific goals for mastering course content have not yet developed as with the academic achieved student. The negative correlation with performance approach goals possibly reflect that the student in academic moratorium has yet to develop a sense of self-efficacy in a specific area or in college as a whole.

As mentioned above, commitment may be an important factor in the types of goals students adopt. Locke and Latham (2002) argue that the relationship between performance and goals is strongest when there is a commitment to the goals. Berzonsky (2003) stated that commitment is a mediator between identity processing styles and outcome behaviors. The findings from this study showed that there is a positive correlation between AIM Achievement and the AGQ-Mastery subscales which demonstrated our hypotheses. Our interpretation of this is that the students who are in an academic identity achievement state are more firmly committed to learning or task goals. Based on the theoretical assumptions about the consequences of mastery achievement goals, students who are mastery oriented use more learning strategies, preferred tasks that offered challenge, and have more positive attitude toward their class. Simultaneously, it is not surprising, then, that this study generated a coherent negative relationship between AIM-Achievement and the AGO-Performance-Avoidant.

The findings of the current study hold a number of implications for educators in both secondary and higher education settings. As a group, the author's of the current study are interested in implications of academic identity status in regards to the transition of students from high school to college, as well as the implications for college retention. 


\section{References}

Ames, C. (1992). Classrooms: Goals, structures, and student motivation. Journal of Educational Psychology, 84, 261-271.

Ames, C. \& Archer, J. (1988). Achievement goals in the classroom. Students' learning strategies and motivation process. Journal of Educational Psychology, 80, 260-267.

Anderman, E. M., \& Young, A. J. (1994). Motivation and strategy use in science: Individual differences and classroom effects. Journal of Research in Science Teaching, 31, 811831.

Archer, S. L. (1993). Identity in relational contexts: A methodological proposal. In J. Kroger (Ed.), Discussions on ego identity. Hillsdale, NJ: Lawrence Erlbaum Associates.

Bandura, A. (1977). Self-efficacy: Toward a unity theory of behavioral change. Psychological Review, 84(2), 191-215.

Bandura, A. (1991). Self-regulation of motivation through anticipatory and self-reactive mechanisms. In R. Dienstbier (Series Ed.) \& R. Dienstbier (Vol. Ed.) Nebraska symposium on motivation: Vol, 38. Perspectives on motivation (pp. 69-164). Lincoln: University of Nebraska Press.

Berger, K. S. (1998). The Developing Person Through the Life Span $\left(4^{\text {th }}\right.$ ed.). New York: Worth.

Berzonsky, M. D. (1989). The self as a theorist: Individual differences in identity formation. International Journal of Personal Construct Psychology, 2, 363-376.

Berzonsky, M. D. (1990). Self-construction over the life-span: A process perspective on identity formation. Advances in Personal Construct Psychology, 1, 155-186.

Berzonsky, M. D. (1992). Identity style and coping strategies. Journal of personality, 60(4), 771-788.

Berzonsky, M. D. (1997). Identity development, control theory and self-regulation: An individual differences perspective. Journal of Adolescent Research, 12(3), 347-353.

Berzonsky, M. D. (2003). The structure of identity: Commentary on Jane Kroger's view of identity status transition. Identity, 3(3), 231-245.

Berzonsky, M. D. (2004). Identity style, parental authority, and identity commitment. Journal of Youth and Adolescence, 33(3).

Berzonsky, M. D., \& Adams, G. R. (1999). Reevaluating the identity status paradigm: Still useful after 35 years. Developmental Review, 19(4), 557-590. 
Berzonsky, M. D., \& Kinney, A. (1995, February). Identity style and need for cognitive closure. Paper presented at the biennial meetings of the Society for Research on Identity Formation, Dog Island, FL.

Berzonsky, M. D., \& Kuk, L. S. (2000). Identity status, identity processing style, and the transition to university. Journal of Adolescent Research, 15(1), 81.

Berzonsky, M. D., \& Kuk, L. S. (2005). Identity style, psychosocial maturity, and academic performance. Personality \& Individual Differences, 39(1), 235-247.

Berzonsky, M. D., Nurmi, J., Kinney, A., \& Tammi, K. (1999). Identity processing style and cognitive attributional strategies: Similarities and difference across different contexts. European Journal of Personality, 13(2), 105-120.

Boyd. V. S,. Hunt, P. F., Kandell, J. J., \& Lucas, M. S. (2003). Relationship between identity processing style and academic success in undergraduate students. Journal of College Student Development, 44(2), 155-167.

Brophy, J. (2005). Goal theorists should move on from performance goals. Educational Psychologist, 40(3), 167-176.

Browne, M. W., \& Cudeck, R. (1992). Alternative ways of assessing model fit. Sociological Methods and Research, 92( 2) 230-259.

De la Fuente, J. (2004). Recent perspectives in the study of motivation: Goal orientation theory. Electronic Journal of Research in Educational Psychology, 2(1), 35-62.

Dweck, C. S. (1986). Motivational processes affecting learning. American Psychologist, 41, 1040-1048.

Dweck, C. S., \& Elliott, E. S. (1983). Achievement motivation. In P. Mussen \& E. M. Heatherington, (Eds.), Handbook of child psychology (Vol. 4, pp. 643-693), New York: Wiley.

Dweck, C. S., \& Leggett, E. L. (1988). A social-cognitive approach to motivation and personality. Psychological Review, 95, 256-273.

Elliot, A. J. (1999). Approach and avoidance motivation and goals. Educational Psychologist, 34(3), 169-189.

Elliot, A. J. (2005). A conceptual history of the achievement goal construct. In A. Elliot \& C. Dweck (Eds.), Handbook of competence and motivation. New York: Guilford Press.

Elliot, A. J., \& Church, M. (1997). A hierarchical model of approach and avoidance achievement motivation. Journal of Personality and Social Psychology, 72, 218-232. 
Elliot, A. J., \& Harackiewicz, J. (1996). Approach and avoidance achievement goals and intrinsic motivation: A mediational analysis. Journal of Personality and Social Psychology, 70, 968-980.

Elliot, E., \& Dweck, C. S. (1988). Goals: An approach to motivation and achievement. Journal of Personality and Social Psychology, 54, 5-12.

Epstein, S. (1973). The self-concept revisited: Or a theory of a theory. American Psychologist, $28,404-416$.

Erikson, E. (1963). Childhood and Society (2 ${ }^{\text {nd }}$ ed.). New York: Norton.

Erikson, E. H. (1968). Identity, Youth, and Crisis. New York: Norton.

Erickson, E. H. (1980). Identity and the Life Cycle ( $2^{\text {nd }}$ ed.). New York: Norton.

Garcia, T., \& Pintrich, P. R. (1995, April). Assessing students' motivation and learning strategies: The motivated strategies for learning questionnaire. Paper presented at the annual of the American Education Research Association, San Fransisco, CA.

Harackiewicz, J. M., Barron, K. E., \& Elliot, A. J. (1998). Rethinking achievement goals;: When are they adaptive for college students and why? Educational Psychologist, 33, $1-21$.

Lange, C., \& Byrd, M. (2002). Differences between students' estimated and attained grades in a first-year introductory psychology course as a function of identity development. $\mathrm{Ad}$ olescence, 37(145), 93-107.

Lepper, M. (1988). Motivational considerations in the study of instruction. Cognition and Instruction, 5(4), 289-309.

Locke, E. A., \& Latham, G. P. (2002). Building a practically useful theory of goal setting and task motivation: A 35-year odyssey. American Psychologist, 57(9), 705-717.

Marcia, J. E. (1966). Development and validation of ego identity status. Journal of Personality and Social Psychology, 3, 351-358.

Marcia, J. E. (1980). Identity in adolescence. In J. Adelson (Ed.), Handbook of adolescent Psychology (pp. 159-187). New York: Wiley.

Marcia, J. E. (1993). The status of statuses: Research review. In J. E. Marcia, A. S. Waterman, D. R. Matteson, S. L. Archer, \& J. L. Orlofsky (Eds.), Ego Identity: A Handbook for Psychosocial Research (pp. 22-41). New York: Springer-Verlag.

Marcia, J. E., \& Archer, S. L. (1993). Identity status in late adolescence: Scoring criteria. In: J.E. Marcia, A.S. Waterman, D.R. Matteson, S.L. Archer and J.L. Orlofsky, (Eds), Identity: A Handbook for Psychosocial Research (pp. 205-240). Springer, New York. 
Marsh, H. W. (1990). The structure of academic self-concept: The Marsh/Shavelson model. Journal of Educational Psychology, 82(4), 623-636.

Marsh, H. W. (1993). The multidimensional structure of academic self-concept: Invariance over gender and age. American Educational Research Journal, 30(4), 841-860.

Marsh, H. W., Byrne, B. M., \& Shavelson, R. (1988). A multifaceted academic self-concept: Its hierarchical structure and its relation to academic achievement. Journal of Educational Psychology, 80(3), 366-380.

Marsh, H. W, \& Yeung, A. S. (1997). Causal effects of academic self-concept on academic achievement: Structural equation models of longitudinal data. Journal of Educational Psychology, 89(1), 41-54.

Meece, J. L., Blumenfeld, P. C, \& Hoyle, R. H. (1988). Students' goal orientation and cognitive engagement in classroom activities. Journal of Educational Psychology, 80, 514523.

Melgosa, J. (1987). Development and validation of the occupational identity scales. Journal of Adolescence, 10(4), 385-397.

Middleton, M., Kaplan, A., \& Midgley, C. (1998). Achievement goal orientation and selfefficacy: Different goals, different relations. Paper presented at the annual meeting of the American Educational Research Association, San Diego, CA.

Middleton, M., \& Midgley, C. (1997). Avoiding the demonstration of lack of ability: An underexplored aspect of goal theory. Journal of educational psychology, 89, 710-718.

Midgley, C., \& Urdan, T. (1995). Predictors of middle school students' use of selfhandicapping strategies. Journal of Early Adolescence, 15, 389-411.

Nolen, S. B. (1988). Reason for studying: Motivational orientations and study strategies. Cognition and Instructions, 5, 269-287.

Pascerrella, E. T., \& Terenzini, P. T. (2005). How College Affects Students, Volume 2: A Third Decade of Research. Jossey-Boss, San Francisco, CA.

Pintrich, P. R., National Center for Research to Improve Postsecondary Teaching and Learning,Ann Arbor, MI, \& And Others. (1991). A manual for the use of the motivated strategies for learning questionnaire (MSLQ)

Sankaran, S., Bui, T. (2001). Impact of learning strategies and motivation on performance: A study in Web-Based instruction. Journal of Instructional Psychology, 28(3), 191-198.

Schank, R. C., \& Ableson, R. P, (1977). Scripts, Plans, Goals, and Understanding: An Inquiry into Human Knowledge Structures. Hillsdale, NJ: Lawrence Earlbaum. 
Schmidt, J. A., \& Hunt, P. F., (1994). Relationship between pre-college attributes and subsequent development in college students. Journal of College Student Development, 35, 481-485.

Shavelson, R. J., Hubner, J. J., \& Stanton, G. C. (1976). Self-concept: Validation of construct interpretations. Review of Educational Research, 46(3), 407-441.

Somuncuoglu, Y., \& Yildirim, A. (1999). Relationship between achievement goal orientations and use of learning strategies. Journal of Educational Research, 92(5), 267-277.

Streitmatter, J. L. (1989). Identity development and academic achievement in early adolescence. Journal of Early Adolescence, 9(2), 99-116.

Was, C. A., \& Isaacson, R. M. (2008). The Development of a Measure of Academic Identity Status. Journal of Research in Education, 18, 94-105.

Wolters, C. A., Yu, S. L., \& Pintrich, P. R. (1996). The relation between goals orientation and students' motivational beliefs and self-regulated learning. Learning and Individual Differences, 8, 211-238. 
Christopher A. Was et al.

[Page intentionally left blank] 